\title{
Dendritic cells pulsed with tumor cells killed by high hydrostatic pressure induce strong immune responses and display therapeutic effects both in murine TC-1 and TRAMP-C2 tumors when combined with docetaxel chemotherapy
}

\author{
ROMANA MIKYŠKOVÁ ${ }^{1,2^{*}}$, IVAN ŠTĚPÁNEK ${ }^{1,2^{*}}$, MARIE INDROVÁ ${ }^{1,2}$, \\ JANA BIEBLOVÁ ${ }^{1,2}$, JANA ŠÍMOVÁ ${ }^{1,2}$, IVA TRUXOVÁ ${ }^{4}$, IRENA MOSEROVÁ ${ }^{4}$, JITKA FUČÍKOVÁ ${ }^{3,4}$, \\ JIŘINA BARTƯŇKOVÁ ${ }^{3,4}$, RADEK ŠPÍŠEK ${ }^{3,4}$ and MILAN REINIŠ ${ }^{1,2}$ \\ ${ }^{1}$ Department of Transgenic Models of Diseases, Institute of Molecular Genetics of the ASCR, v.v.i., Prague; \\ ${ }^{2}$ Czech Centre for Phenogenomics, Institute of Molecular Genetics of the ASCR, Prague; ${ }^{3}$ Department of Immunology, \\ Charles University, 2nd Faculty of Medicine and University Hospital Motol, Prague; ${ }^{4}$ SOTIO a.s., Prague, Czech Republic
}

Received October 20, 2015; Accepted December 2, 2015

DOI: $10.3892 /$ ijo.2015.3314

\begin{abstract}
High hydrostatic pressure (HHP) has been shown to induce immunogenic cell death of cancer cells, facilitating their uptake by dendritic cells (DC) and subsequent presentation of tumor antigens. In the present study, we demonstrated immunogenicity of the HHP-treated tumor cells in mice. HHP was able to induce immunogenic cell death of both TC-1 and TRAMP-C2 tumor cells, representing murine models for human papilloma virus-associated tumors and prostate cancer, respectively. HHP-treated cells induced stronger immune responses in mice immunized with these tumor cells, documented by higher spleen cell cytotoxicity and increased IFN $\gamma$ production as compared to irradiated tumor cells, accompanied by suppression of tumor growth in vivo in the case of TC-1 tumors, but not TRAMP-C2 tumors. Furthermore, HHP-treated cells were used for DC-based vaccine antigen pulsing. DC co-cultured with HHP-treated tumor cells and matured by a TLR 9 agonist exhibited higher cell surface expression of maturation markers and production of IL-12 and other cytokines, as compared to the DC pulsed with irradiated tumor cells. Immunization with DC cellbased vaccines pulsed with HHP-treated tumor cells induced high immune responses, detected by increased spleen cell
\end{abstract}

Correspondence to: Dr Milan Reiniš, Czech Centre for Phenogenomics, Institute of Molecular Genetics of the Academy of Sciences of the Czech Republic, v.v.i., Vídeňská 1083, 14220 Prague 4, Czech Republic

E-mail: milan.reinis@img.cas.cz

${ }^{*}$ Contributed equally

Key words: dendritic cells, docetaxel, high hydrostatic pressure, immunotherapy, cancer cytotoxicity and elevated IFN $\gamma$ production. The DC-based vaccine pulsed with HHP-treated tumor cells combined with docetaxel chemotherapy significantly inhibited growth of both TC-1 and TRAMP-C2 tumors. Our results indicate that DC-based vaccines pulsed with HHP-inactivated tumor cells can be a suitable tool for chemoimmunotherapy, particularly with regard to the findings that poorly immunogenic TRAMP-C2 tumors were susceptible to this treatment modality.

\section{Introduction}

Cancer immunotherapy, especially when combined with other therapeutic modalities such as chemotherapy, is an attractive approach to cancer treatment. Synergistic effects of combinations of immunotherapy and chemotherapy have been demonstrated in a number of pre-clinical and clinical studies $(1,2)$.

Dendritic cells (DCs) are key players in the immune response as they are able to capture antigens with their pattern-recognition receptors, to process and present them to naïve T-cells, inducing their activation (3), and thus building an essential bridge between innate and adaptive responses. The possibility of their generation in vitro enabled their use for immunotherapy of cancer (4), and a number of clinical trials have been performed in the last decade $(5,6)$. Typically, an autologous dendritic cell-based vaccine represents in vitro cultured dendritic cells pulsed with tumor antigens that can be in the form of tumor cells with subsequent DC maturation. For DC pulsing, tumor cells can be inactivated by their lysis (ultrasonic treatment, repeated freeze-thaw), lethal irradiation or other methods before mixing them with DC. Selection of the optimal inactivation method can be crucial for DC vaccine optimization, together with selection of proper maturationinducing agents.

Therefore, a significant effort has also been invested in increasing the immunogenicity of dying cancer cells used 
for vaccine production. Until now several chemotherapeutic agents [anthracyclines (7), oxaliplatin, platinum complexes (8), bortezomib (9)] and physical modalities [UV-C, irradiation (10), HHP] have been identified as inducers of immunogenic cell death (ICD). ICD is characterized by the cell-surface expression and release of damage associated molecular patterns (DAMPs). DAMPs found to be crucial for ICD include surface exposed chaperone protein calreticulin (CRT) and heat shock proteins 70 (HSP70) and 90 (HSP90), actively secreted ATP and passively released high-mobility group box 1 protein (HMGB1). These signals can activate innate immunity and, importantly, interact with phagocytosis-related receptors, purinergic receptors and pattern-recognition receptors expressed by DCs and thereby stimulate presentation of tumor antigens to $\mathrm{T}$ cells.

High hydrostatic pressure (HHP) has been demonstrated as a convenient tool for tumor cell inactivation preserving their immunogenic capacity $(11,12)$. Recently, induction of ICD by HHP has been shown in several human tumor cell lines. HHP-treated cells were able to induce monocyte-derived DC maturation, and DC co-cultured with HHP-treated tumor cells were able to induce $\mathrm{T}$ cell activation in vitro. These encouraging results suggest that HHP can be an important tool for tumor cell inactivation before their use for DC pulsing or as cellular vaccines (13).

Chemotherapeutic drugs affect rapidly growing cells and, as a consequence, cause collateral damage to cells of the immune system. In this regard, they are considered immunosuppressive. However, there is increasing evidence that some cancer chemotherapies may actually aid the immunotherapy by activating the immune system rather than suppressing it $(14,15)$. Chemotherapeutic drugs such as cyclophosphamide, doxorubicin, paclitaxel or docetaxel (16) were reported to possess immunomodulatory activities and appeared to be suitable for chemoimmunotherapy $(17,18)$.

Docetaxel is a widely used chemotherapeutic drug and represents a first-line chemotherapy for metastatic castrationresistant prostate cancer $(19,20)$. The autologous dendritic cell-based vaccines are intensively studied as an immunotherapy for prostate cancer, and the first cellular immunotherapy based on activated peripheral blood mononuclear cells, Sipuleucel T, has been FDA-approved (21). Collectively, combination chemoimmunotherapy based on docetaxel combined with the DC treatment represents an attractive modality for advanced prostate cancer therapy.

In the present study, we investigated, using murine tumor models, the immunogenicity of the HHP-inactivated tumor cells in vivo and, furthermore, the possibility to use HHP-treated tumor cells for preparation of DC-based vaccines. We have demonstrated the therapeutic capacity of the HHP cells-pulsed DC vaccines in combination with docetaxel treatments to inhibit growth of the TRAMP-C2 and TC-1 murine tumors. We have focused on the immunotherapy of poorly immunogenic TRAMP-C2 tumors, an animal model of prostate cancer treatment. For comparison, the study was completed with experiments using immunogenic TC-1 tumors representing a murine model for human papilloma virus 16 -associated tumors, previously shown to be sensitive to the experimental DC treatments in various settings (22-24).

\section{Materials and methods}

Mice. C57BL/6 male mice, 6-8 weeks old, were obtained from AnLab Ltd., Prague, Czech Republic. Experimental protocols were approved by the Institutional Animal Care Committee of the Institute of Molecular Genetics, Prague.

Tumor cell lines. The TC-1 tumor cell line (obtained from the ATCC collection) was developed by co-transfection of murine C57BL/6 lung cells with HPV16 E6/E7 genes and activated (G12V) Ha-ras plasmid DNA (25). TRAMP-C2 tumor cells (obtained from the ATCC collection), MHC class I-deficient, were established from a heterogeneous 32-week tumor of the transgenic adenocarcinoma mouse prostate (TRAMP) model (26). TC-1 cells were maintained in RPMI-1640 medium (Sigma-Aldrich GmbH, Steinheim, Germany) supplemented with 10\% FCS (PAN Biotech GmbH, Aidenbach, Germany), $2 \mathrm{mM}$ L-glutamine and antibiotics; TRAMP-C2 cells were maintained in D-MEM medium (Sigma-Aldrich) supplemented with 5\% FCS, Nu-Serum IV (5\%; BD Biosciences, Bedford, MA, USA), $0.005 \mathrm{mg} / \mathrm{ml}$ human insulin (Sigma-Aldrich), dehydroisoandrosterone (DHEA, $10 \mathrm{nM}$; Sigma-Aldrich) and antibiotics. Both cell lines were cultured at $37^{\circ} \mathrm{C}$ in a humidified atmosphere with $5 \% \mathrm{CO}_{2}$ cells. In the in vivo experiments, $5 \times 10^{4}$ TC- 1 cells and $1 \times 10^{6}$ TRAMP-C2 cells were administered for the challenge. In our hands, $5 \times 10^{4}$ TC-1 cells represent 5 TID $_{50}$ doses and $1 \times 10^{6}$ TRAMP-C2 cells represent 3 TID $_{50}$ doses.

High hydrostatic pressure and irradiation cell treatments. Tumor cells were treated by HHP (100, 150, 175 and $200 \mathrm{MPa})$ in the custom-made device (Resato International BV, Roden, the Netherlands) that is located in the GMP manufacturing facility, Sotio a.s. (Prague, Czech Republic). This device allows reliable treatment of the tumor cells by defined levels of HHP for specified periods of time (10 $\mathrm{min}$ in the case of $200 \mathrm{MPa})$ (13). Inactivation of tumor cells by irradiation (150 Gy) was performed as previously described (22).

Dendritic cell preparation. Dendritic cells (DC) were prepared from bone marrow precursors as described by Indrová et al (24) and Lutz et al (27) with slight modifications (28). Briefly, the bone marrow cells were cultured for 7 days in the complete RPMI-1640 medium supplemented with $2 \times 10^{-5} \mathrm{M}$ mercaptoethanol (Calbiochem, La Jolla, CA, USA), $10 \mathrm{ng} / \mathrm{ml}$ GM-CSF and IL-4 (R\&D Systems, Minneapolis, MN, USA). On day 5, the DC were pulsed with HHP-treated or irradiated (IR-treated) tumor cells by 48 -h incubation in the ratio of 2:1 (DC/tumor cells, $\left.10^{6} \mathrm{DC} / \mathrm{ml}\right)$. DC pulsed with the tumor cells were treated for $24 \mathrm{~h}$ with unmethylated $\mathrm{CpG}$ containing phosphorothioate-modified oligodeoxynucleotide CpG 1826 (5'-TCCATGACGTTCCTGACGTT-3') (29) at a final concentration of $5 \mu \mathrm{g} / \mathrm{ml}$ (Generi Biotech, Hradec Králové, Czech Republic), were sulfur-modified in their backbone (phosphorothioate) and synthesized under endotoxin-free conditions. On day 7, non-adherent cells were harvested. These cells, designated as DC, contained $\sim 60-70 \% \mathrm{CD} 1 \mathrm{c}^{+}$ cells. For mouse immunization experiments, DC were washed twice with PBS and injected subcutaneously (s.c.) in PBS, $300 \mu 1 / 2 \times 10^{6}$ cells/mouse. 
Immunization/challenge experiments with tumor cells. Mice were twice immunized with $5 \times 10^{6}$ irradiated tumor cells in a three-week interval (s.c., irradiation dose was $150 \mathrm{~Gy}$, HHP dose was $200 \mathrm{MPa})(13,30,31)$. For in vivo studies, 10 days after the second immunization, mice were challenged s.c. with corresponding tumor cells (TC-1, 5x104; TRAMP-C2, $1 \times 10^{6}$ cells/mouse). Mice were observed twice weekly, and the numbers of tumor-bearing mice and the size of the tumors were recorded. Two perpendicular diameters of the tumors were measured with a caliper and the tumor size was expressed as the tumor area $\left(\mathrm{cm}^{2}\right)$. For in vitro analyses of the immune response, three mice were sacrificed. Single-cell suspensions from the spleens were prepared by homogenization through a cell strainer (70 $\mu \mathrm{m}$; BD Biosciences, San Jose, CA, USA). Erythrocytes were osmotically lysed using ammonium chloride-potassium lysis buffer, the cell suspension was washed three times in the RPMI-1640 medium and used for further analysis by FACS, chromium release assay, ELISA (IFN $\gamma$ ) and ELISPOT (IFN $\gamma)$.

Immunization/challenge experiments with dendritic cells. Mice were twice immunized with $2 \times 10^{6}$ cells of DC-based vaccine in a two-week interval. For in vivo studies, 10 days after the second immunization, mice were challenged s.c. with corresponding tumor cells (TC-1, 5x10 ${ }^{4}$; TRAMP-C2, $1 \times 10^{6}$ cells/mouse). Mice were observed twice weekly, and the numbers of tumor-bearing mice and the size of the tumors were recorded. Two perpendicular diameters of the tumors were measured with a caliper and the tumor size was expressed as the tumor area $\left(\mathrm{cm}^{2}\right)$. For in vitro analyses of the immune response, three mice were sacrificed. Single-cell suspensions from the spleens were prepared as mentioned above and used for further analysis by FACS, chromium release assay, ELISA $(\mathrm{IFN} \gamma)$ and ELISPOT (IFN $\gamma)$.

Therapeutic experiments. The therapeutic schemes were designed for combined chemoimmunotherapy treatment of early growing tumors. TC-1 $\left(5 \times 10^{4}\right.$ cells $)$ or TRAMP-C2 $\left(1 \times 10^{6}\right.$ cells) tumor cells were s.c. transplanted on day 0 . Docetaxel, $30 \mathrm{mg} / \mathrm{kg}$ (Actavis, North Bruncwik, NJ, USA) was repeatedly administered on days 7,21 and 35 intraperitoneally (i.p.). Dendritic cells were administered on days 14, 28 and 42 in the vicinity of the tumor cell challenge site or peritumorally when the growing tumors appeared. Mice were observed twice a week and the size of the tumors was recorded. Two perpendicular diameters of the tumors were measured with a caliper and the tumor size was expressed as the tumor area $\left(\mathrm{cm}^{2}\right)$.

Flow cytometry. Cell surface expression of CRT, HSP90, MHC class I, CD54 and CD80 on the tumor cells was analyzed by flow cytometry. Tumor cells were collected from the cell culture $24 \mathrm{~h}$ after the HHP or IR treatment $\left[10^{6}\right.$ cells/ml/well, 12-well plate (Nunc, Roskilde, Denmark)]. Cells $\left(5 \times 10^{5} /\right.$ sample) were washed and labeled with primary antibodies for $25 \mathrm{~min}$ at $4^{\circ} \mathrm{C}$, followed by wash steps and alternatively labeled by incubation with Alexa 647- or DyLight 649-conjugated secondary antibody for $30 \mathrm{~min}$ at $4^{\circ} \mathrm{C}$. Apoptotic cells were determined by Annexin V apoptosis detection kit (eBiosciences) according to the manufacturer's instructions. Samples were kept in the dark and 10 min before the analysis, Hoechst 33258 was added at a final concentration of $2 \mu \mathrm{g} / \mathrm{ml}$. Expression of cell surface molecules on the DC or spleen cells was analyzed by flow cytometry. Cell suspensions were washed and preincubated with anti-CD16/CD32 antibody to minimize non-specific binding for $15 \mathrm{~min}$ at $4^{\circ} \mathrm{C}$ following washing step and incubation with labeled primary antibody for $30 \mathrm{~min}$ at $4^{\circ} \mathrm{C}$. Relevant isotype controls of irrelevant specificity were used. FACS buffer (PBS, $1 \% \mathrm{FBS}, 0.1 \% \mathrm{NaN}_{3}$ ) was used for all washing steps and analysis. The following antibodies were used for FACS analyses: BD: anti-MHC class I (PE anti-H-2D ${ }^{\mathrm{b}}$ clone KH95 and PE anti-H-2K $\mathrm{K}^{\mathrm{b}}$ clone AF6-88.5), FITC anti-I-A ${ }^{b}\left(A_{\beta}^{b}\right)$ (AF6-120.1), PE anti-CD54 (3E2), PE anti-CD80 (16-10A1), PE anti-CD86 (GL1), PE anti-CD274 (MIH5); BioLegend, Inc. (San Diego, CA, USA): BV421 or APC anti-CD11c (HL3), APC-CD45 (30-F11), FITC anti-CD8 $\alpha$ (LY-2), BV711 anti-CD4 (RM4-5), PE anti-CD44 (IM7), PE-Cy7 CD62L (MEL-14); R\&D Systems (Basel, Switzerland): anti-HSP70 (242707); Abcam (Cambridge, UK): anti-CRT (ab2907); Enzo Life Sciences, Inc. (Farmingdale, NY, USA): anti-HSP90 (AC88). Secondary antibodies antimouse conjugated to DyLight 649 (Jackson ImmunoResearch Laboratories, West Grove, PA, USA) or anti-rabbit conjugated to Alexa 647 (Cell Signaling Technology, Danvers, MA, USA) were also used. FACS analysis was performed using an LSR II flow cytometer (BD Biosciences) and analyzed by FlowJo 7.6.5 software.

Confocal microscopy. HHP-treated TC-1 and TRAMP-C2 cells were collected and washed twice with PBS. The cells were then incubated for $30 \mathrm{~min}$ with primary anti-CRT antibody (FMC 75; Enzo Life Sciences) diluted in PBS, followed by washing and incubation with the Alexa Fluor 488 goat antimouse secondary antibody (Molecular Probes). Cells were washed twice with PBS and fixed in $4 \%$ paraformaldehyde for $20 \mathrm{~min}$ and mounted on slides. Cells were examined under a DMI 6000 inverted Leica TCS AOBS SP5 tandem scanning confocal microscope with an AR (488 nm) laser and an x63 oil immersion objective.

ELISA. For HMGB1 release, supernatants from the tumor cell culture were collected $24 \mathrm{~h}$ after HHP treatment $\left(10^{6}\right.$ cell/ml/well, 12-well plate (Nunc) and analyzed by an ELISA kit (IBL International GmbH, Hamburg, Germany) according to the manufacturer's instructions. For IL-1 $\beta$, IL-6, IFN $\gamma$ and IL-12 production, supernatants from the DC culture were collected $24 \mathrm{~h}$ after the addition of CpG 1826 and analyzed by ELISA kits (BD Biosciences) according to the manufacturer's instructions. For IFN $\gamma$ production, supernatants from the spleen single-cell suspension were collected after 48 -h incubation $\left[2 \times 10^{6} \mathrm{cell} / \mathrm{ml} /\right.$ well, 12 -well plate (Nunc)] and analyzed by an ELISA kit (BD Biosciences) according to the manufacturer's instructions.

ELISPOT. To determine the amount of IFN $\gamma$-secreting cells, an ELISPOT kit for detection of murine IFN $\gamma$ (BD Biosciences, San Diego, CA, USA) was used. Spleen cells were cultured for $48 \mathrm{~h}$ and then placed into the wells of ELISPOT plates (concentration $5 \times 10^{5}, 1 \times 10^{5}$ and $5 \times 10^{4}$ cells/well) for $24 \mathrm{~h}$. The plates were then processed according to the manufacturer's instructions (BD Biosciences). Colored spots were counted 

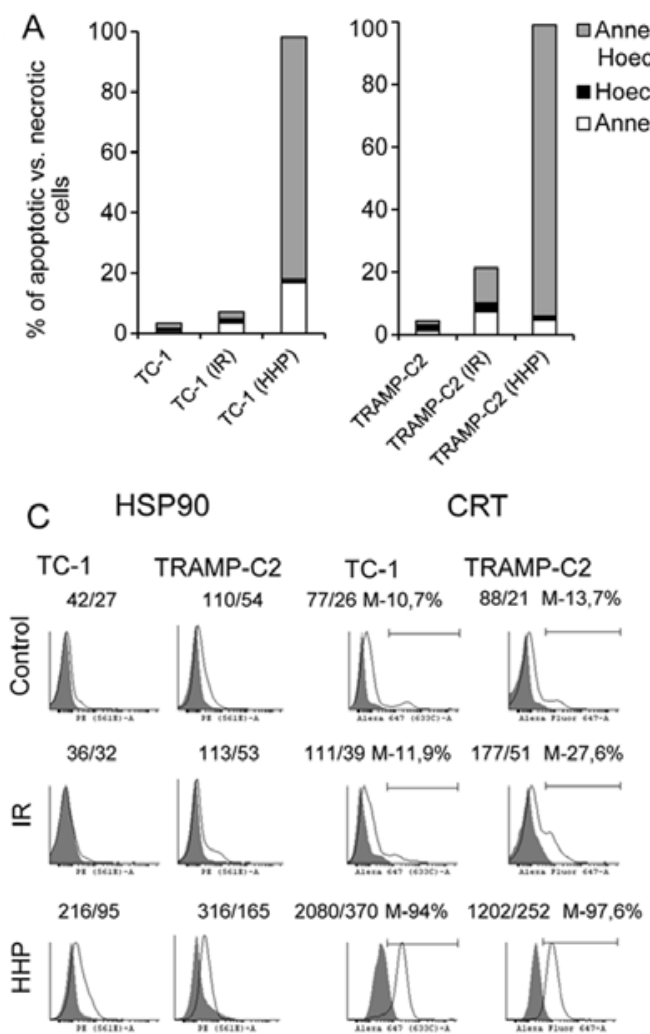
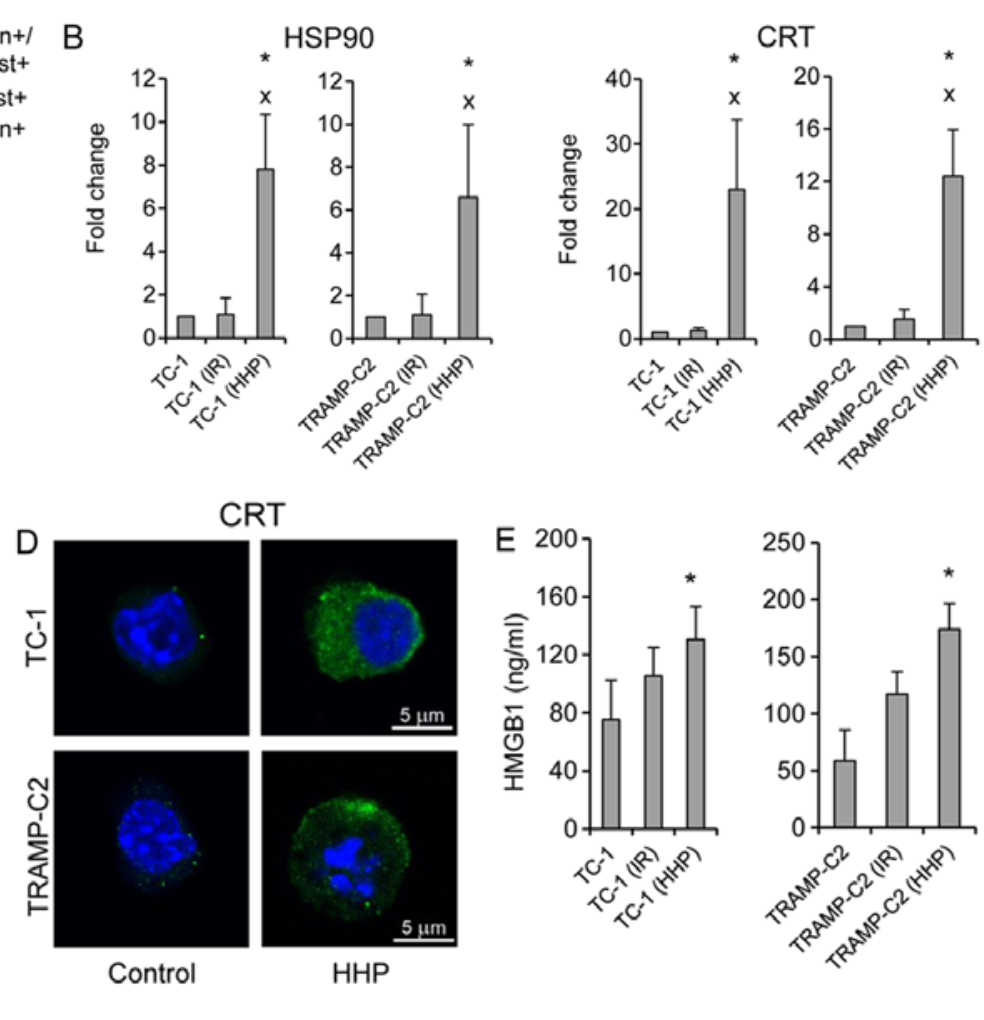

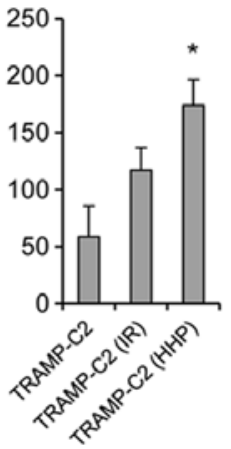

Figure 1. Phenotype of mouse TC-1 and TRAMP-C2 tumor cells $24 \mathrm{~h}$ after the treatment with HHP or IR. TC-1 and TRAMP-C2 tumor cells were treated with $200 \mathrm{MPa}$ for $10 \mathrm{~min}$ and compared with irradiated (150 Gy) tumor cells. (A) Annexin V/Hoechst staining made $24 \mathrm{~h}$ after HHP or IR treatment. (B and C) Expression of cell surface molecules HSP90 and CRT on TC-1 or TRAMP-C2 tumor cells (presented as a fold change of mean fluorescence intensity (MFI) or histograms with MFI). (D) Fluorescence microscopy images of HHP-treated TC-1 and TRAMP-C2 tumor cells stained for CRT expression. (E) Release of HMGB1 into the tumor cell supernatants after HHP or IR-treatment. Representative results from at least three independent experiments. ${ }^{*} \mathrm{P}<0.05$ vs. untreated control, ${ }^{x} \mathrm{P}<0.05$ vs. IR treated group, two-sided Student's t-test.

with CTL Analyzer LLC (CTL, Cleveland, OH, USA) and analyzed using ImmunoSpot Image Analyzer software.

Chromium release microcytotoxicity assay. The cytolytic activity of effector cells was tested in $18-\mathrm{h}{ }^{51} \mathrm{Cr}$ release assay, as previously described $(32,33)$. Briefly, spleen cells from control and immunized mice that served as effector cells were treated with ammonium chloride-potassium lysing buffer (1 min) to deplete erythrocytes. The mixtures of effector cells with ${ }^{51} \mathrm{Cr}$-labeled tumor targets were incubated in selected target/ effector cell ratios $(1: 25,1: 50,1: 100$ and 1:200) in triplicate in 96-well round bottom microtiter plates (Nunc). The percentage of specific ${ }^{51} \mathrm{Cr}$ release was expressed according to the formula: [cpm experimental release - cpm control release/cpm maximum release/cpm control release] x 100 .

Statistical analyses. For statistical analyses of in vitro experiments, Student's t-test was used. For evaluation of in vivo experiments, analysis of variance (ANOVA) from the NCSS, Number Cruncher Statistical System (NCSS, LLC, Kaysville, UT, USA) statistical package was utilized. Standard deviations are indicated in the figures.

\section{Results}

HHP, but not IR, induces ICD markers on both TC-1 and TRAMP-C2 tumor cells. First, we determined the ability of
HHP to induce ICD in murine TC-1 or TRAMP-C2 cells, and then we compared the effect of HHP to the effect of irradiation $(150 \mathrm{~Gy})$ that has been standardly used for treatment of cells during preparation of DC vaccines in our previous studies (22). Fig. 1A shows that the percentage of late apoptotic/dead tumor cells (Annexin $\mathrm{V}^{+} /$Hoechst $^{+}$) after the treatment with $200 \mathrm{MPa}$ HHP was $>80 \%$ within $24 \mathrm{~h}$. The presence of ICD markers HSP90 and CRT on the cell surface of the tested cells was also significantly increased (Fig. 2B and C). Fluorescence microscopy images of HHP-treated tumor cells stained for CRT confirmed increased expression of CRT after HHP treatment (Fig. 1D). Release of HMGB1, late-stage ICD marker, in the supernatant was further analyzed. Fig. 1E demonstrates a significant increase of HMGB1 in the tumor cell supernatants after HHP treatment. Induction of ICD by $200 \mathrm{MPa}$ HHP was similar both in TC-1 and TRAMP-C2 tumor cells. No significant upregulation of ICD markers was detected after irradiation with $150 \mathrm{~Gy}$. The treatment with $\mathrm{HHP}$ of $200 \mathrm{MPa}$ was selected as it was the most effective in inducing apoptosis and expression of ICD markers and simultaneously arresting cell proliferation, as determined by colony-forming assay in experiments, in which the effects of different doses of HHP $(100,150,175,200$ and $250 \mathrm{MPa}$ ) were compared (data not shown).

Prophylactic immunization with HHP-treated tumor cells induces higher immune responses in mice when compared 
A

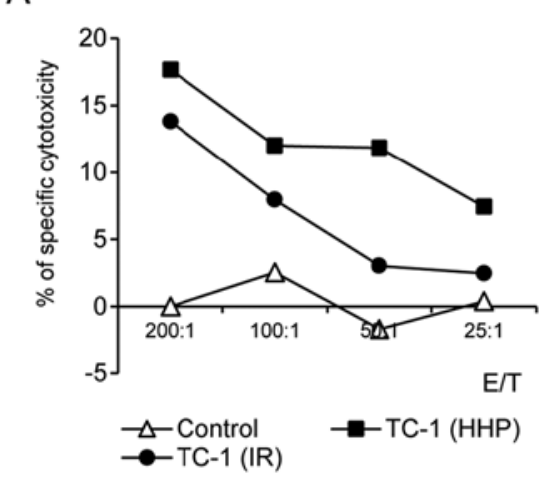

$B$
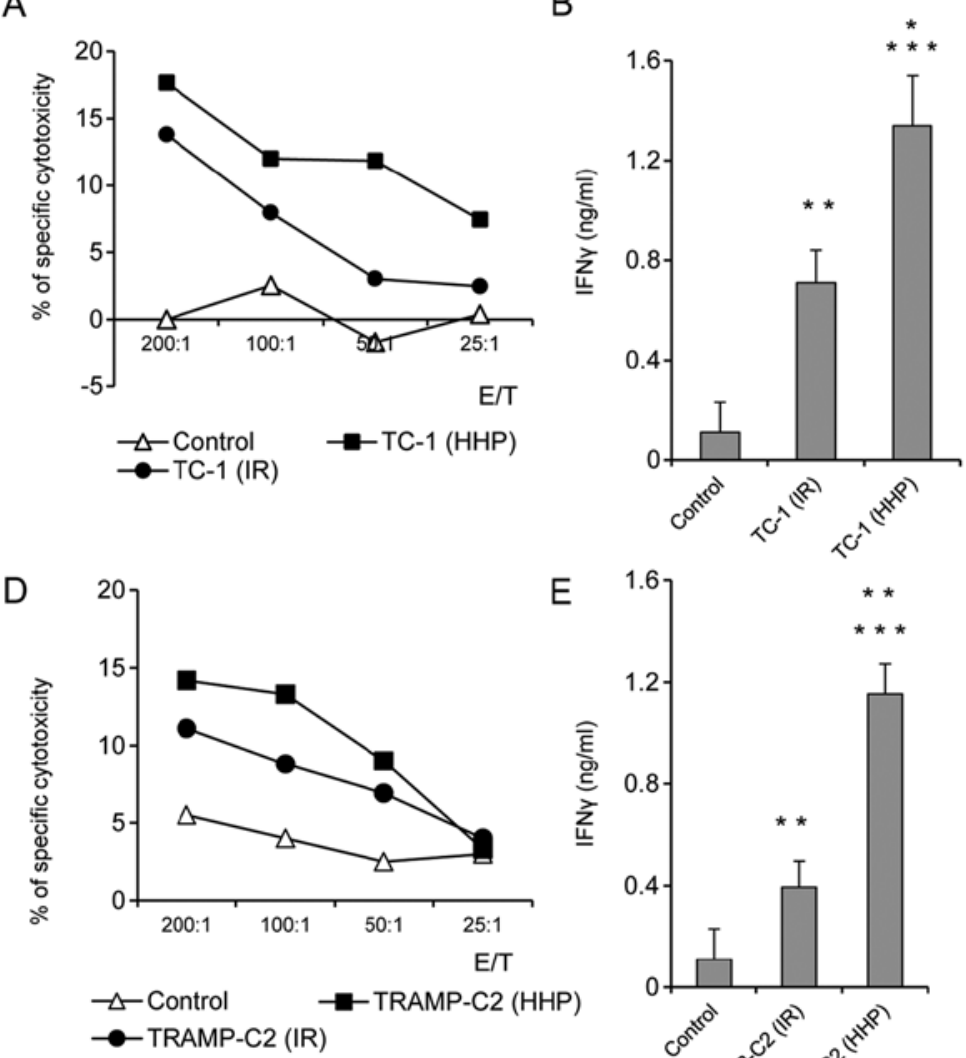

E

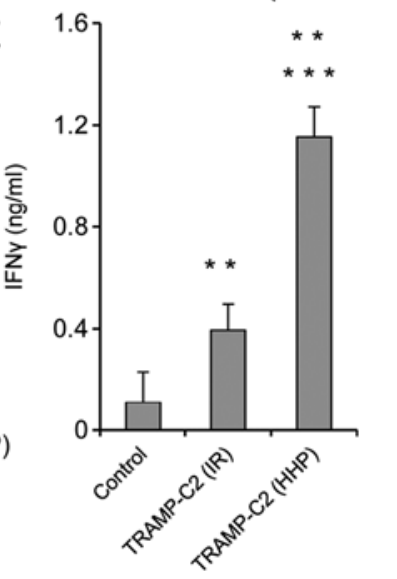

C
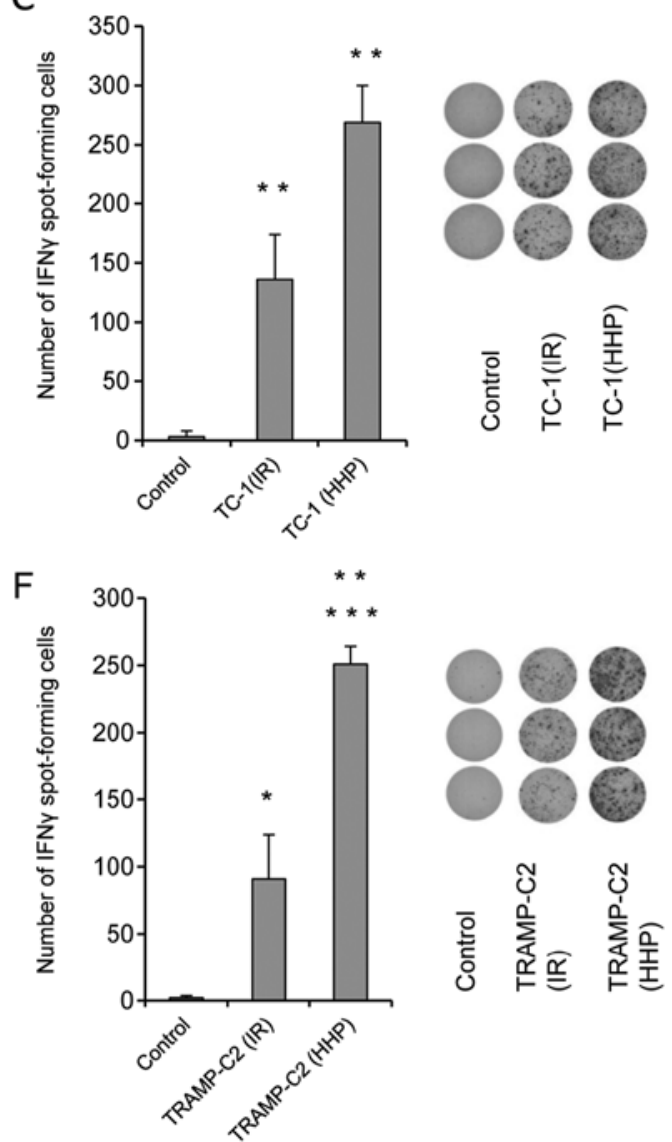

Figure 2. In vitro immune response after immunization with HHP-treated or IR-treated TC-1 and TRAMP-C2 tumor cells. Mice were immunized two times in a 3-week interval with 5x10 ${ }^{6}$ HHP- or IR-treated TC-1 and TRAMP-C2 tumor cells. Ten days after the last immunization, pooled splenocytes of three mice were used for in vitro analysis. ${ }^{51} \mathrm{Cr}$ microcytotoxicity assay of splenocytes from mice immunized with HHP or IR-treated TC-1 (A) or TRAMP-C2 tumor cells (D). (B and E) IFN $\gamma$ production by splenocytes of immunized mice (ELISA). (C and F) The number of IFN $\gamma$-producing cells (ELISPOT assay). Statistical significances were determined by Student's t-test. (B) ${ }^{* * *} \mathrm{P}<0.001$ TC-1(HHP) vs. Control; ${ }^{* *} \mathrm{P}<0.01$ TC-1(IR) vs. Control; ${ }^{*} \mathrm{P}<0.05$ TC-1(HHP) vs. TC-1(IR); (C) ${ }^{* *} \mathrm{P}<0.001$ TC-1(HHP) vs. Control; TC-1(IR) vs. Control; TC-1(HHP) vs. TC-1(IR); (E) ${ }^{* * *} \mathrm{P}<0.001$ TC-1(HHP) vs. Control; ${ }^{* *} \mathrm{P}<0.01 \mathrm{TC}-1(\mathrm{IR})$ vs. Control; TC-1(HHP) vs. TC-1(IR); (F) ${ }^{* * *} \mathrm{P}<0.001$ TC-1(IR) vs. Control; ${ }^{* *} \mathrm{P}<0.01$ TC-1(HHP) vs. TC-1(IR); ${ }^{*} \mathrm{P}<0.05$ TC-1(HHP) vs. Control.

with IR-treated tumor cells both in TC-1 and TRAMP-C2 tumor models. To study the ability of HHP and IR-treated tumor cells to induce immune response and their antitumor potency, mice were immunized twice at a three-week interval with $5 \times 10^{6}$ HHP- or IR-treated TC-1 or TRAMP-C2 tumor cells. Ten days after the second immunization, mice were challenged with relevant tumor cells in doses of $5 \times 10^{4} \mathrm{TC}-1$ or $10^{6}$ TRAMP-C2. Three mice from each group were left without challenge and used for parallel in vitro analyses. In vitro analyses of the spleen effector cells prepared ten days after the second immunization with HHP-treated TC-1 or TRAMP-C2 tumor cells showed an increased cytotoxic effect of spleen effector cells on the corresponding targets. In the group of mice immunized with IR-treated tumor cells, a similar but slightly lower effect was observed (Fig. 2A and D). Despite the fact that the analysis of the spleen effector cells after immunization with HHP-treated tumor cells showed only moderately augmented cytotoxic effect when compared to immunization with IR-treated tumor cells, analysis of IFN $\gamma$ production revealed significant differences. Compared to the IR-treated tumor cells, mice immunized with HHP-treated tumor cells displayed significantly increased IFN $\gamma$ production by spleen cells measured by the ELISA assay (Fig. 2B and E) and signifi- cantly increased number of IFN $\gamma$-producing cells detected by the ELISPOT assay (Fig. 2C and F). These results were similar in both tumor models, immunogenic TC-1 and weakly immunogenic TRAMP-C2. However, after the challenge of immunized mice with the corresponding tumor cells, significant inhibition $(\mathrm{P}<0.05)$ of tumor growth was recorded only in the groups of mice immunized with the HHP or IR-treated TC-1 tumor cells and challenged with corresponding TC-1 cells (Fig. 3B). In contrast, mice immunized with HHP and IR-treated TRAMP-C2 cells did not exhibit any inhibition of tumor growth after the challenge with TRAMP-C2 cells (Fig. 3C).

Pulsing with HHP-treated TC-1 or TRAMP-C2 tumor cells increased expression of maturation markers on $D C$ and stimulated production of cytokines characteristic for matured DC. Next, the HHP-treated TC-1 and TRAMP-C2 cells were used for DC pulsing, and the phenotypes of matured DC vaccines, unpulsed or pulsed with the IR-treated tumor cells or HHP-treated tumor cells, were compared (Fig. 4). We did not see any significant differences between unpulsed cells and HHP-treated tumor cells-pulsed DC. In both cases, CpG ODN1826-mediated maturation increased 
A

\begin{tabular}{lcccc}
$\begin{array}{c}\text { tumor cells } \\
\text { (IR or HHP treated) }\end{array}$ & $\begin{array}{c}\text { tumor cells } \\
\text { (IR or HHP treated) }\end{array}$ & $\begin{array}{c}\text { challenge } \\
\text { TC-1 or } \\
\text { TRAMP-C2 }\end{array}$ \\
\hline Week & -5 & -2 &
\end{tabular}

B

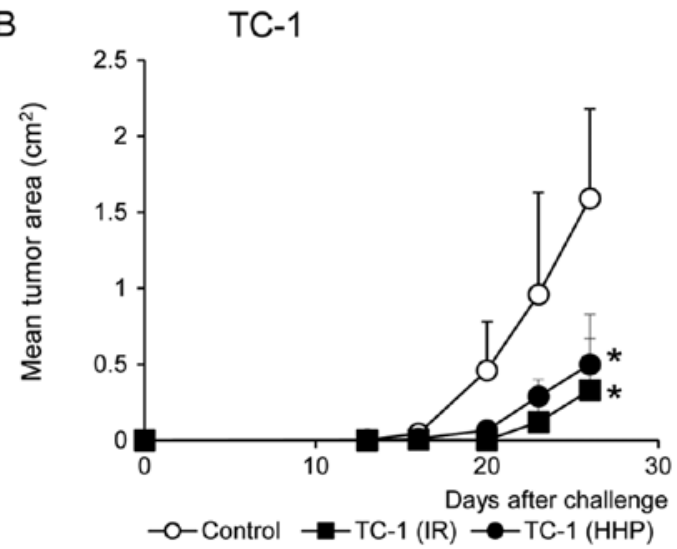

C

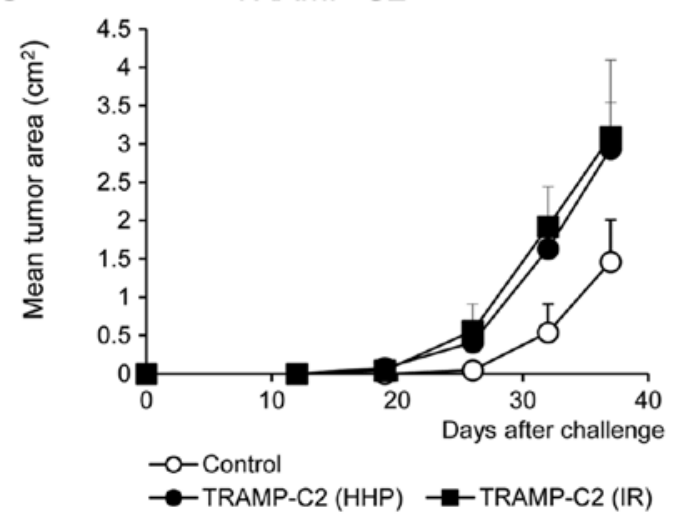

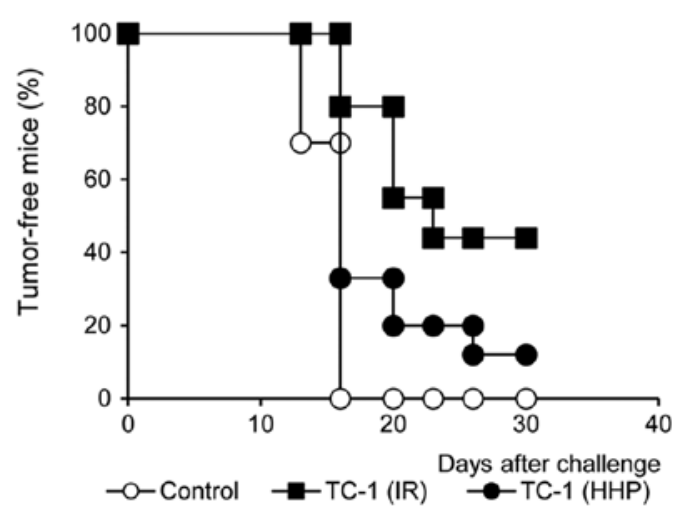

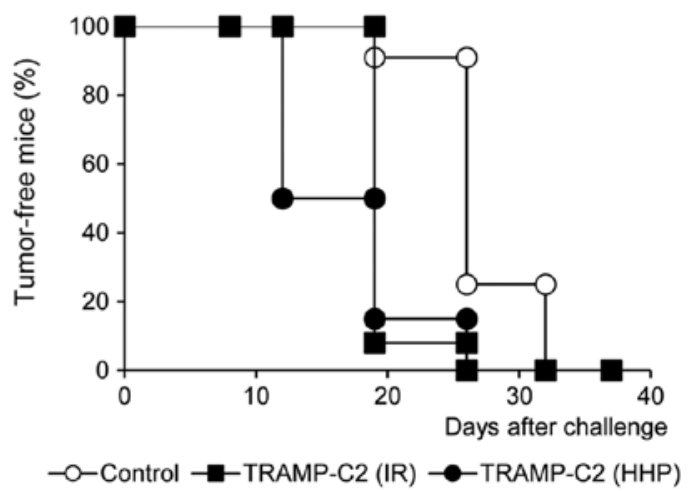

Figure 3. The effect of immunization with HHP-treated or IR-treated TC-1 and TRAMP-C2 tumor cells. Mice (10 mice per group) were two times s.c. immunized in a 3-week interval with 5x10 ${ }^{6}$ HHP- or IR-treated TC-1 and TRAMP-C2 tumor cells (A). Ten days after the second immunization, mice were challenged with $5 \times 10^{4} \mathrm{TC}-1$ (B) or $10^{6} \mathrm{TRAMP}-\mathrm{C} 2$ (C) tumor cells. Tumor growth (left panel) and the percentage of tumor-free mice (Kaplan-Maier plot) (right panel) are shown; TC-1, $\mathrm{P}<0.05$ (untreated vs. HHP-treated, IR-treated). TRAMP-C2, not significant (analysis of variance). The experiments were repeated twice with similar results.

the proportion of matured $\mathrm{MHC}$ class $\mathrm{II}^{\text {high }} / \mathrm{CD} 86^{\text {high }}$ dendritic cells and increased CD80 and CD274 cell surface expression (Fig. 4A and B). The ratio between the CD80 and CD274 cell surface expressions (demonstrated by MFI values) was higher on matured cells compared to the immature controls (Fig. 4A). Both unpulsed cells and HHP-treated tumor cells-pulsed matured DC produced IL-12, as well as IL-1 $\beta$, IL-6 and IFN $\gamma$ (Fig. 4C). HHP-treated tumor cellpulsed matured DC produced significantly higher amounts of IL-12 and IFN $\gamma$ as compared to the unpulsed cells. No significant differences were observed between TRAMP-C2 and TC-1 cell co-culture. On the other hand, pulsing with the IR-treated tumor cells resulted in reduction of the proportion of matured MHC class $\mathrm{II}^{\text {high }} / \mathrm{CD} 86^{\text {high }}$ dendritic cells in the DC populations, decreased the ratio between the CD80 and CD274 cell surface expression, and also significantly inhibited IL-12, IFN $\gamma$ and IL-1 $\beta$ production, as compared to both unpulsed cells and HHP-treated tumor cell-pulsed matured DC (Fig. 4). These results indicate that DC co-culture with IR-treated, but not HHP-treated tumor cells, can impair DC maturation.
Prophylactic immunization with DC-based vaccine pulsed with HHP-treated TC-1 or TRAMP-C2 tumor cells induces strong immune response, but inhibits growth of TC-1 tumors only. In the next series of experiments, HHP-treated tumor cell-pulsed matured DC were investigated in vivo. HHP-treated tumor cell-pulsed matured DC were selected for further in vivo experiments as pulsing of DC with IR-treated tumor cells negatively affected DC maturation in terms of expression of costimulatory molecules and production of selected cytokines. Mice were immunized twice in a 2-week interval with $2 \times 10^{6}$ HHP-treated tumor cell-pulsed matured DC. Ten days after the second immunization, mice were challenged with relevant tumor cells, in doses of $5 \times 10^{4} \mathrm{TC}-1$ or $10^{6}$ TRAMP-C2 tumor cells. Three mice from each group were left without challenge and used for parallel in vitro analyses. Both HHP-treated TRAMP-C2 and TC-1 cells pulsed DC vaccines induced strong immune responses, as determined by spleen cell analysis performed ten days after the second immunization (Fig. 5). Immunization with HHP-treated TC-1 or TRAMP-C2 pulsed DC vaccines showed a significantly increased cytotoxic effect of spleen effector cells on the 
A
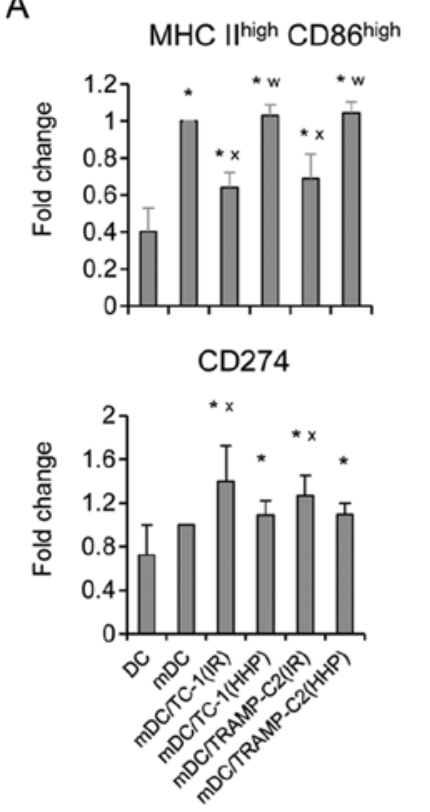

C

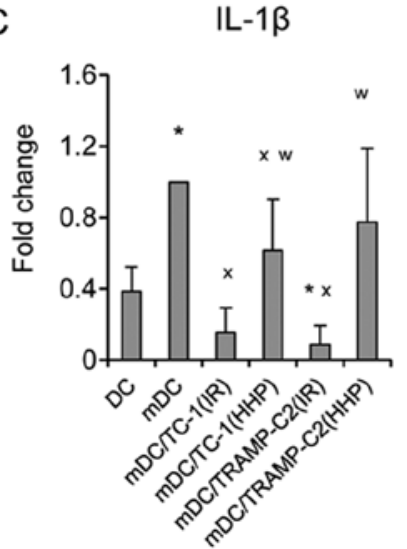

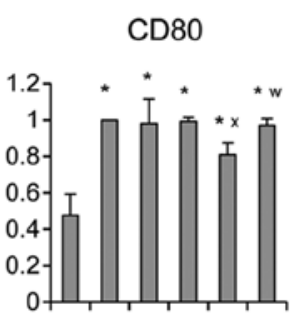

$\mathrm{CD} 80 / \mathrm{CD} 274$

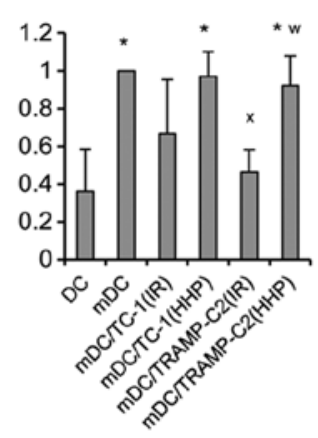

IL-6
B

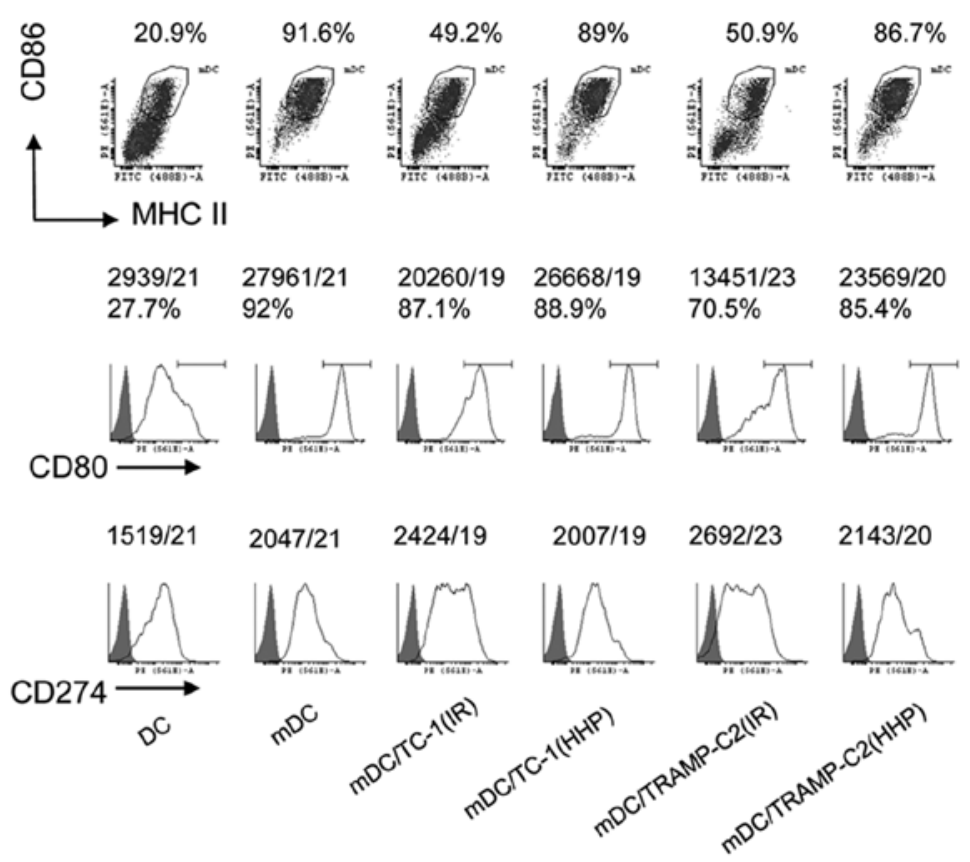

IL-12

IFNY
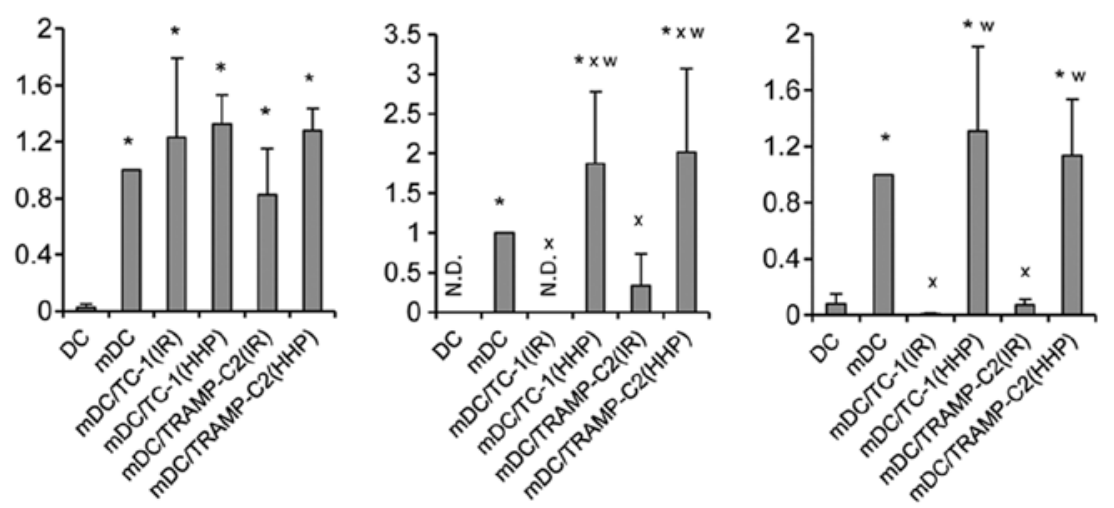

Figure 4. Phenotype of mouse DC after the interaction with HHP- or IR-treated TC-1 or TRAMP-C2 tumor cells. DC were prepared from bone marrow precursors and pulsed with HHP- or IR-treated tumor cells by 48 -h incubation in the ratio of 2:1. DC pulsed with the tumor cells were then treated for $24 \mathrm{~h}$ with $\mathrm{CpG}$ 1826 and analyzed by flow cytometry. (A and B) Expression of MHC class II and costimulatory molecules (as a fold change of MFI or as a dot plot/histograms with MFI). (C) Production of cytokines by DC culture (as a fold change relative to mature DC designated as mDC). mDC produced IL-1 $\beta$ in the range of $233-749 \mathrm{pg} / \mathrm{ml}, \mathrm{IFN} \gamma$ in the range of $299-749 \mathrm{pg} / \mathrm{ml}$, IL-6 in the range of 18.2-49.2 ng/ml, and IL-12 in the range of $760-2235 \mathrm{pg} / \mathrm{ml}$. Representative results from at least four independent experiments. ${ }^{*} \mathrm{P}<0.05$ vs. $\mathrm{DC},{ }^{\mathrm{x}} \mathrm{P}<0.05$ vs. $\mathrm{mDC},{ }^{\mathrm{w}} \mathrm{P}<0.05$ vs. DC pulsed with IR-treated tumor cells, Student's t-test.

corresponding targets (Fig. 5A). As compared with control mice, mice immunized with both HHP-treated TRAMP-C2 and TC-1 cells pulsed DC vaccines displayed significantly increased numbers of IFN $\gamma$-producing cells detected by ELISPOT assay (Fig. 5B) and significantly increased IFN $\gamma$ production by spleen cells measured by ELISA assay (Fig. 5C). A significant increase was also found in the percentage of $\mathrm{CD}^{+}$and $\mathrm{CD}^{+} \mathrm{CD}^{+} 4^{+} \mathrm{CD} 2 \mathrm{~L}^{-} \mathrm{T}$ lymphocytes (Fig. 5D and $\mathrm{E})$. These results were similar in both tumor models, immunogenic TC-1 and weakly immunogenic TRAMP-C2. Contrary to the results in vitro, in vivo analysis showed significant inhibition $(\mathrm{P}<0.05)$ of the tumor growth only in the group of mice immunized with the HHP-treated TC-1 tumor cell-pulsed matured DC and challenged with corresponding TC-1 cells (Fig. 6B). Mice immunized with the HHP-treated TRAMP-C2 tumor cell-pulsed matured DC did not exhibit any inhibition of tumor growth after the challenge with TRAMP-C2 cells
(Fig. 6C). In both experiments, the percentage of tumor-free mice are shown in the right panel.

Combined chemoimmunotherapy of TC-1 and TRAMP-C2 tumors with docetaxel and DC-based vaccine significantly inhibits growth of subcutaneous tumors. The therapeutic efficacy of HHP-treated tumor cell-pulsed matured DC was then tested in the therapeutic setting when a combination of chemotherapy and immunotherapy with DC-based vaccine

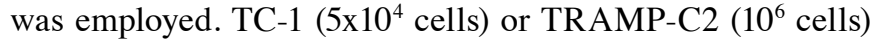
tumor cells were s.c. transplanted on day 0 and treated with three doses of docetaxel chemotherapy in a 2-week interval. Dendritic cells were administered at regular intervals between the docetaxel chemotherapy. As shown in Fig. 7B, the growth of immunogenic TC-1 tumors was significantly inhibited by the treatment with $\mathrm{DC}$ alone or with the combination of docetaxel and DC vaccine [DC/TC-1(HHP)] $(\mathrm{P}<0.05$ vs. 

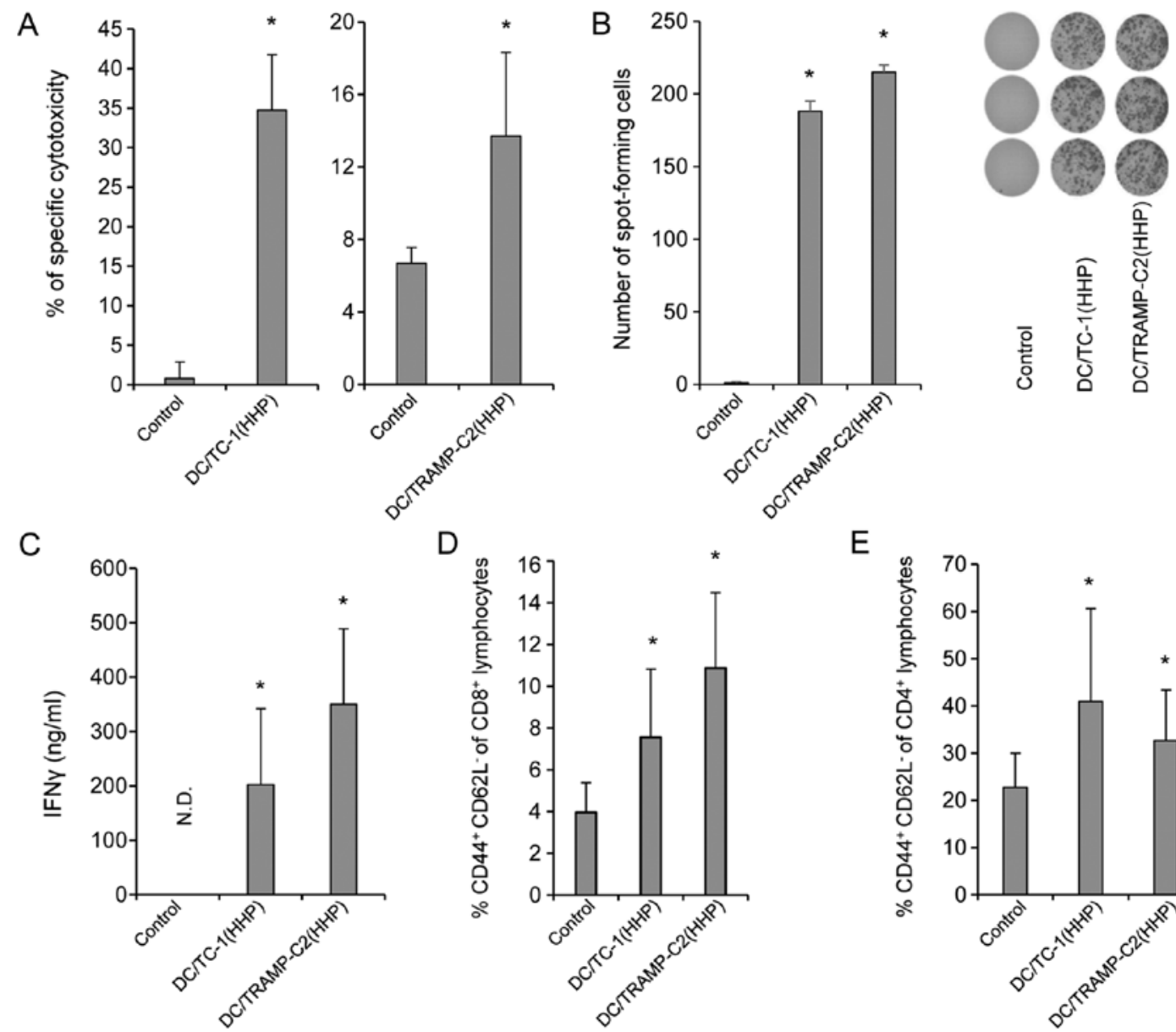

$\mathrm{E}$

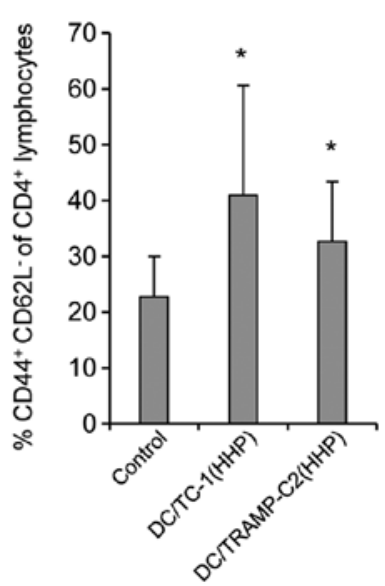

Figure 5. In vitro immune response after immunization with DC-based vaccines pulsed with HHP-treated TC-1 or TRAMP-C2 tumor cells. Mice were immunized two times in a 2-week interval with $2 \times 10^{6}$ DC pulsed with HHP-treated TC-1 or TRAMP-C2 tumor cells. Ten days after the last immunization, pooled splenocytes of three mice were used for in vitro analysis. ${ }^{51} \mathrm{Cr}$ microcytotoxicity assay of splenocytes from mice immunized with HHP- and IR-treated TC-1 tumor cells or TRAMP-C2 tumor cells (A). (B) The number of IFN $\gamma$-producing cells (ELISPOT assay). (C) IFN $\gamma$ production by splenocytes of immunized mice (ELISA). N.D. means that IFN $\gamma$ production was under detection limit and for Student's t-test was considered as 0. (D) Percentage of CD44 ${ }^{+}$CD62L- of $\mathrm{CD}^{+}$lymphocytes. (E) Percentage of CD44+ CD62L- of CD4 ${ }^{+}$lymphocytes. Statistical significance was determined by Student's t-test; "P<0.05 vs. control.

control). Docetaxel alone delayed the growth of tumors, but no significant difference was evident. A representative experiment of two independent ones is given in Fig. 7B. When the incidences of tumors in mice from two performed experiments were merged [Control 19/19, docetaxel 18/20, docetaxel + DC/ TC-1(HHP) 14/19, DC/TC-1-HHP 6/10], the only significant difference was found between the control group and the group of combined chemoimmunotherapy $\left(\chi^{2} ;\right.$ docetaxel $+\mathrm{DC} / \mathrm{TC}-1(\mathrm{HHP})$ vs. Control $\mathrm{P}<0.01)$. These results indicate the beneficial effect of the combination of chemotherapy with immunotherapy. The same therapeutic setting was also used for the treatment of poorly immunogenic TRAMP-C2 tumors. As shown in Fig. 7C, monotherapies with docetaxel alone or DC/TRAMP-C2(HHP) vaccine alone significantly inhibited growth of TRAMP-C2 tumors. However, when these monotherapies were combined, the therapeutic effect was even stronger. Significant inhibition of tumor growth was found between docetaxel alone or DC/TRAMP-C2(HHP) alone groups and the group treated with a combination of docetaxel and DC/TRAMP-C2(HHP) vaccine $(\mathrm{P}<0.05)$. The tumorinhibitory effect was noted as reduction of the size of growing tumors; there was no difference between the incidences of tumors when two independent experiments were merged
[Control 25/26, docetaxel 22/22, docetaxel + DC/TRAMPC2(HHP) 22/22, DC/TRAMP-C2(HHP) 21/22].

\section{Discussion}

HHP has been previously shown to induce endoplasmic reticulum stress and consequently ICD in both murine and human cell lineages $(11,13,34)$. This suggests that HHP, along with other modalities, such as irradiation, photodynamic therapy using hypericin, hyperthermia or treatments with selected chemotherapeutic and cytotoxic agents, can be used for preparation of tumor cells capable of inducing effective antitumor immunity (35). HHP could also be used for tumor cell inactivation before their use as cellular vaccines or as antigen donors in DC-based vaccines.

In the first part of the study, our aim was to demonstrate the capability of HHP-treated tumor cells to induce immune responses in mice, in comparison with irradiated tumor cells. Lethal irradiation represents a standard procedure used for tumor cell inactivation before their usage for immunization or for DC pulsing, and HHP treatment can serve as an attractive alternative for this procedure. Before performing the in vivo experiments, we optimized the HHP treatments of 
A

\begin{tabular}{cccc} 
DC \& & DC \& & $\begin{array}{c}\text { challenge } \\
\text { TC-1 or } \\
\text { TRAMP-C2 }\end{array}$ \\
\hline Week & -4 & -2 & 0
\end{tabular}

B

TC-1
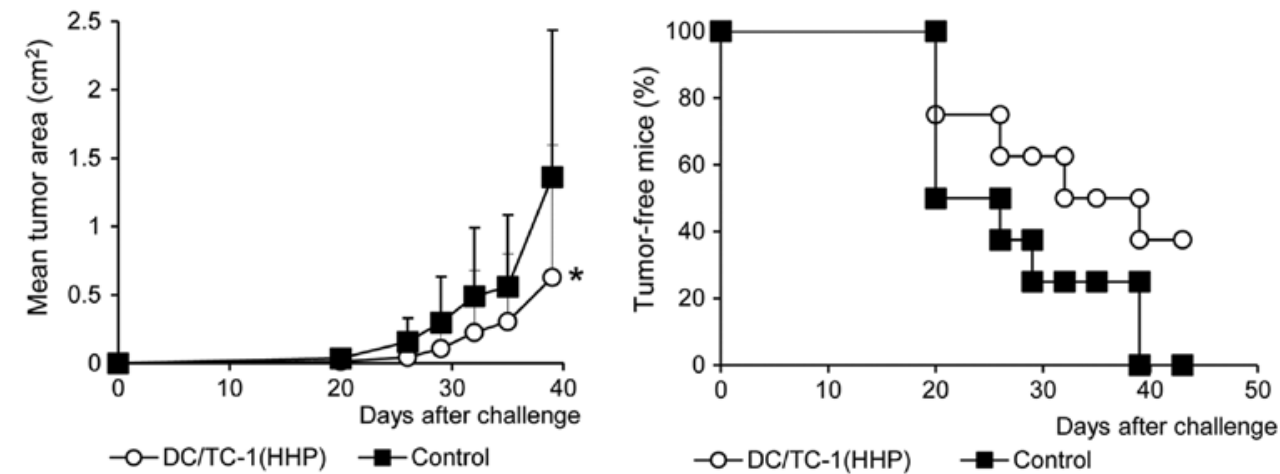

C

TRAMP-C2

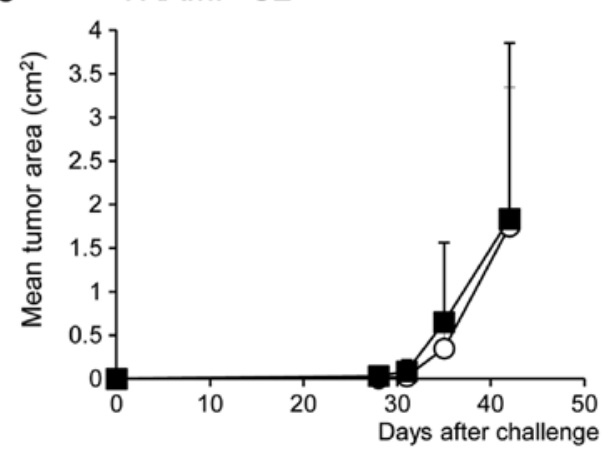

-O-DC/TRAMP-C2(HHP)

- Control

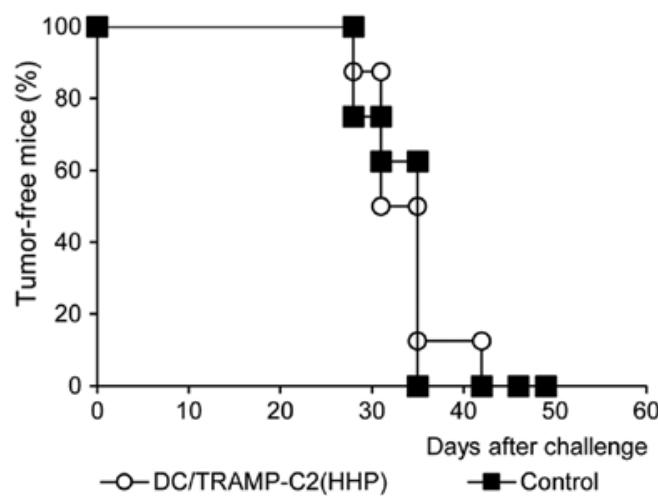

Figure 6. The effect of immunization with DC-based vaccines pulsed with HHP-treated TC-1 or TRAMP-C2 tumor cells. Mice (8 mice per group) were two times s.c. immunized in a 2-week interval with $2 \times 10^{6}$ DC pulsed with HHP-treated TC-1 or TRAMP-C2 tumor cells (A). Ten days after the second immunization, mice were challenged with $5 \times 10^{4} \mathrm{TC}-1$ (B) or $1 \times 10^{6}$ TRAMP-C2 (C) tumor cells. Tumor growth (left panel) and the percentage of tumor-free mice (Kaplan-Maier plot) (right panel) are shown; ${ }^{*} \mathrm{P}<0.05$ vs. control (analysis of variance). The experiments were repeated twice with similar results.

TC-1 and TRAMP-C2 cell lines used for the studies and we demonstrated, in comparative experiments, that HHP induced higher levels of CRT and HSP90 expression on tumor cells, as well as HMGB1 production, as compared to irradiation. The immunogenicity of irradiated and HHP-treated cells was further monitored in vivo and we noted higher IFN $\gamma$ production by spleen cells upon immunization with the HHP-treated compared to irradiated cells. However, we did not observe significantly higher cytotoxicity of the spleen cells from the animals immunized with HHP-treated cells and this finding was in agreement with the results of immunization-challenge experiments. We did not see any significant differences between vaccination with HHP- or IR-treated tumor cells; both vaccinations inhibited TC-1 tumor growth, as expected and previously observed for the animals immunized with IR-treated cells $(30,31)$ while the TRAMP-C2 tumor growth was not blocked by both of the vaccination protocols. It has been previously shown that TRAMP-C2 tumor cells are not immunogenic, unless their immunogenicity was increased by IFN $\gamma$ treatment, inducing MHC class I cell surface expression (36). Thus, it seems that HHP treatment, which induces ICD but not MHC class I and co-stimulatory molecule cell surface expression, does not induce protective immunity effec- tive against TRAMP-C 2 cells. It is of note that in the case of TC-1 tumors, which are apparently more sensitive to immune responses, effective immunity was induced by vaccination with both irradiated and HHP-treated TC-1 cells.

Furthermore, in order to assess the suitability of HHP as a tool for tumor cell preparation in the DC-based vaccine preparation protocols, we prepared a DC-based vaccine by co-culture of immature DC with HHP-treated TC-1 or TRAMP-C2 tumor cells and subsequent DC maturation with CpG ODN 1826. CpG ODN 1826, an agonist of Toll-like receptor 9, is a potent maturation agent for murine DC (37), and the capability of DC pulsed by co-cultivation with irradiated tumor cells and matured by CpG ODN 1826 to inhibit the TC-1 tumor growth has also been demonstrated in our laboratory (38). We have compared the phenotype of matured DC vaccines, unpulsed or pulsed with the IR- or HHP-treated tumor cells. The results suggest that DC co-culture with irradiated, but not HHP-treated tumor cells, interferes with their subsequent $\mathrm{CpG}$ ODN-driven maturation, since the matured DC culture of the cells pulsed with IR-treated cells displayed lower proportion of matured DC (defined as MHC class $\mathrm{II}^{\text {high }} / \mathrm{CD} 6^{\text {high }}$ ), and lower ratio between the expression of positive costimulatory molecule CD80 (B7.1) vs. negative 
A

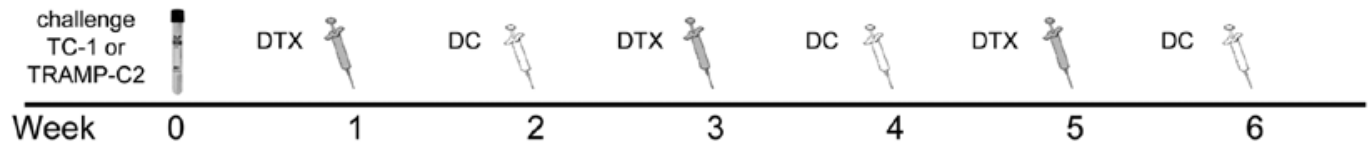

B

TC-1
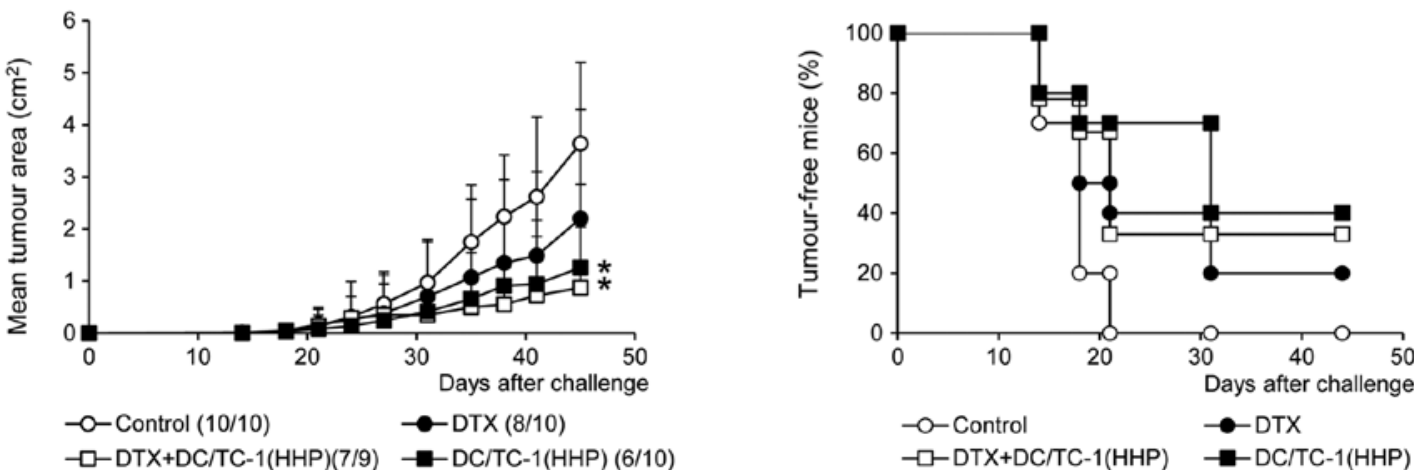

C

TRAMP-C2
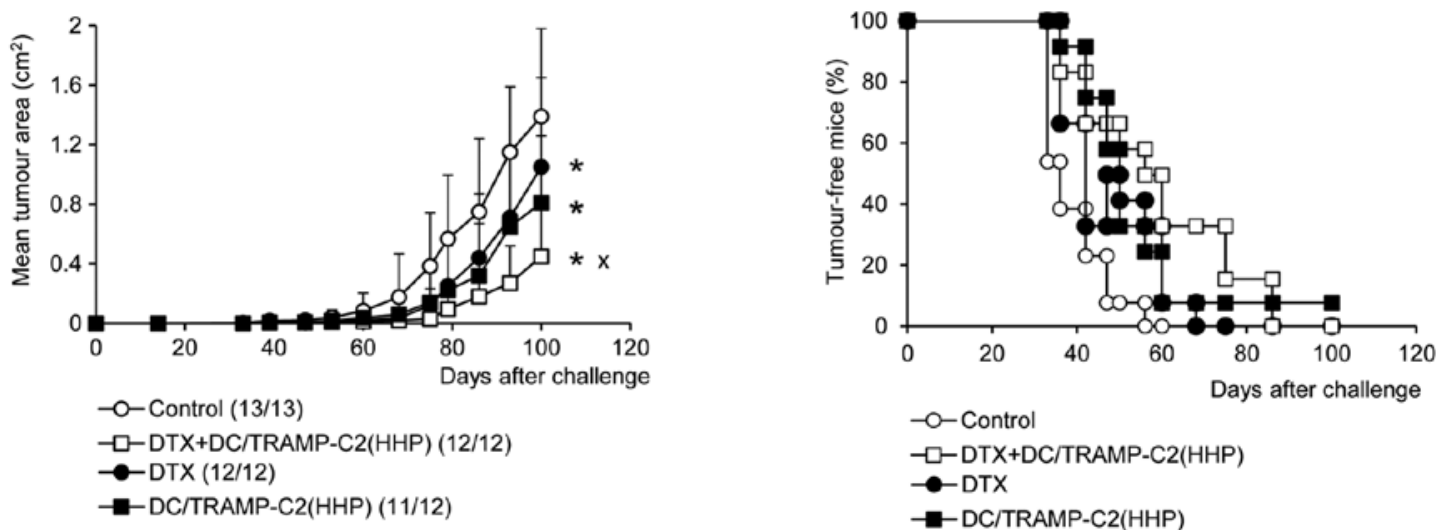

Figure 7. Combined chemoimmunotherapy of TC-1 or TRAMP-C2 tumors. (A) TC-1 (5x10 $0^{4}$ cells) or TRAMP-C2 $\left(10^{6}\right.$ cells) tumor cells were s.c. transplanted on day 0. Docetaxel (DTX) was i.p. administered in a dose of $30 \mu \mathrm{g} / \mathrm{kg}$, on days 7, 21 and 35 . Dendritic cells ( $2 \times 10^{6}$ cells) were s.c. administered peritumorally on days 14, 28 and 42. (B) Tumor growth (left panel) of TC-1 tumors and the percentage of tumor-free mice (Kaplan-Maier plot) (right panel). (C) Tumor growth (left panel) of TRAMP-C2 tumors and the percentage of tumor-free mice (right panel) (Kaplan-Maier plot). Results are representative of two independent experiments. ${ }^{*} \mathrm{P}<0.05$ vs. control, ${ }^{\times} \mathrm{P}<0.05$ vs. DC/TRAMP-C2(HHP), DTX (analysis of variance).

costimulatory molecule CD274 (B7-H1). This ratio can be considered as an important marker suggesting the DC capability to transmit positive signaling to T cells (39). Selected cytokine expression levels, including that of IL-12, were lower in DC pulsed with IR-treated tumor cells, as compared to the unpulsed controls. Notably, this was not observed when the HHP-treated tumor cells DC were compared to the unpulsed controls. These results suggest that immature DC co-culture with HHP-treated cells represents a convenient protocol for the DC-based vaccine preparation and corroborates previous findings of Fucikova et al (13).

The next step was therefore to perform in vivo experiments and to evaluate the immunogenicity of the matured DC pulsed with the HHP-treated tumor cells. As expected, DC vaccines induced much higher IFN $\gamma$ production by spleen cells as compared to immunization with tumor cells. This, together with further parameters investigated in the spleens (chromium release assay, effector memory CD4 and CD8 cell proportion), suggested that DC vaccines induced strong immunity against TC-1 or TRAMP-C2 tumors, respectively. However, as determined in the immunization-challenge experiments, DC vaccination in a prophylactic setting induced protection against TC-1, but not TRAMP-C2 tumor growth. This was in agreement with IR- and HHP-treated tumor cell immunization, confirming different immunogenicity or sensitivity of the TC-1 and TRAMP-C2 tumors to the immune response induced by prophylactic immunization.

Next, we tested the vaccine efficacy in a therapeutic setting in combination with docetaxel chemotherapy, which is clinically relevant especially for prostate cancer treatment $(19,20)$. DC-based vaccines are in general intended to be used rather for tumor immunotherapy in a multimodal setting than for immunization. In our experiments, unlike in prophylactic use, the DC treatments of both immunogenic TC-1 and poorly immunogenic/treatable TRAMP-C2 tumors resulted in significant inhibition of the tumor growth, albeit the effect on the TRAMP-C2 appeared to be weaker as compared to the TC-1 tumors. The difference was observed for the therapeutic protocol using docetaxel and DC combination. This treatment led to the highest therapeutic effect, as compared to the chemotherapy or immunotherapy only treatments, in the case of the TRAMP-C2 prostate cancer model. In this model, both chemo- and immunotherapy, when used as monotherapies, displayed only moderate antitumor effects, and additive/ 
synergistic effects were observed when these treatments were used in combination. On the contrary, synergistic effects of the combination therapy were not seen for the TC-1 therapy. We can speculate that TC-1 tumors are much more vulnerable to immunotherapy, as compared to the TRAMP-C2 tumors, and that it may be difficult to boost it. Moreover, DTX treatment can increase the TRAMP-C2 tumor cell sensitivity to the immune responses.

In conclusion, in the present study we demonstrated that HHP-treatment induced ICD in the cells of TRAMP-C2 and TC-1 murine tumor cell lines. Furthermore, our results show that DC-based vaccines pulsed with HHP-treated cells is an effective instrument for immunotherapy, mainly when combined with chemotherapy, as has been demonstrated in the prostate cancer TRAMP-C2 model, which is poorly immunogenic and difficult to treat.

\section{Acknowledgements}

The present study was supported by research grant provided by SOTIO a.s., and in part by MEYS (LM2011032), the Academy of Sciences of the Czech Republic (RVO 68378050), the project 'BIOCEV-Biotechnology and Biomedicine Centre of the Academy of Sciences and Charles University' (CZ.1.05/1.1.00/02.0109) from the European Regional Development Fund. The authors are grateful to Mrs. Renáta Turečková for skillful technical assistance and to Dr Š́rka Takáčová for editorial help. Conflict of interest: J. Bartůňková and R. Špišek are employees and shareholders of SOTIO a.s.

\section{References}

1. Ramakrishnan R, Antonia S and Gabrilovich DI: Combined modality immunotherapy and chemotherapy: A new perspective. Cancer Immunol Immunother 57: 1523-1529, 2008.

2. Nowak AK, Lake RA and Robinson BW: Combined chemoimmunotherapy of solid tumours: Improving vaccines? Adv Drug Deliv Rev 58: 975-990, 2006.

3. Banchereau J and Steinman RM: Dendritic cells and the control of immunity. Nature 392: 245-252, 1998.

4. Palucka $\mathrm{K}$ and Banchereau J: Cancer immunotherapy via dendritic cells. Nat Rev Cancer 12: 265-277, 2012.

5. Galluzzi L, Senovilla L, Vacchelli E, Eggermont A, Fridman WH, Galon J, Sautès-Fridman C, Tartour E, Zitvogel L and Kroemer G: Trial watch: Dendritic cell-based interventions for cancer therapy. Oncoimmunology 1: 1111-1134, 2012.

6. Podrazil M, Horvath R, Becht E, Rozkova D, Bilkova P, Sochorova K, Hromadkova H, Kayserova J, Vavrova K, Lastovicka J, et al: Phase I/II clinical trial of dendritic-cell based immunotherapy (DCVAC/PCa) combined with chemotherapy in patients with metastatic, castration-resistant prostate cancer. Oncotarget 6: 18192-18205, 2015.

7. Fucikova J, Kralikova P, Fialova A, Brtnicky T, Rob L, Bartunkova J and Spísek R: Human tumor cells killed by anthracyclines induce a tumor-specific immune response. Cancer Res 71: 4821-4833, 2011

8. Hato SV, Khong A, de Vries IJ and Lesterhuis WJ: Molecular pathways: The immunogenic effects of platinum-based chemotherapeutics. Clin Cancer Res 20: 2831-2837, 2014.

9. Spisek R, Charalambous A, Mazumder A, Vesole DH, Jagannath S and Dhodapkar MV: Bortezomib enhances dendritic cell (DC)-mediated induction of immunity to human myeloma via exposure of cell surface heat shock protein 90 on dying tumor cells: Therapeutic implications. Blood 109: 4839-4845, 2007.

10. Galluzzi L, Kepp O and Kroemer G: Immunogenic cell death in radiation therapy. Oncoimmunology 2: e26536, 2013.
11. Weiss EM, Frey B, Rödel F, Herrmann M, Schlücker E, Voll RE, Fietkau R and Gaipl US: Ex vivo- and in vivo-induced dead tumor cells as modulators of antitumor responses. Ann NY Acad Sci 1209: 109-117, 2010

12. Frey B, Rubner Y, Kulzer L, Werthmöller N, Weiss EM, Fietkau R and Gaipl US: Antitumor immune responses induced by ionizing irradiation and further immune stimulation. Cancer Immunol Immunother 63: 29-36, 2014.

13. Fucikova J, Moserova I, Truxova I, Hermanova I, Vancurova I, Partlova S, Fialova A, Sojka L, Cartron PF, Houska M, et al: High hydrostatic pressure induces immunogenic cell death in human tumor cells. Int J Cancer 135: 1165-1177, 2014.

14. Emens LA: Chemoimmunotherapy. Cancer J 16: 295-303, 2010.

15. Ménard C, Martin F, Apetoh L, Bouyer F and Ghiringhelli F: Cancer chemotherapy: Not only a direct cytotoxic effect, but also an adjuvant for antitumor immunity. Cancer Immunol Immunother 57: 1579-1587, 2008.

16. van Dodewaard-de Jong JM, Verheul HM, Bloemendal HJ, de Klerk JM, Carducci MA and van den Eertwegh AJ: New treatment options for patients with metastatic prostate cancer: What is the optimal sequence? Clin Genitourin Cancer 13: 271-279, 2015.

17. Machiels JP, Reilly RT, Emens LA, Ercolini AM, Lei RY, Weintraub D, Okoye FI and Jaffee EM: Cyclophosphamide, doxorubicin, and paclitaxel enhance the antitumor immune response of granulocyte/macrophage-colony stimulating factor-secreting whole-cell vaccines in HER-2/neu tolerized mice. Cancer Res 61: 3689-3697, 2001 .

18. Malvicini M, Rizzo M, Alaniz L, Piñero F, García M, Atorrasagasti C, Aquino JB, Rozados V, Scharovsky OG, Matar P, et al: A novel synergistic combination of cyclophosphamide and gene transfer of interleukin-12 eradicates colorectal carcinoma in mice. Clin Cancer Res 15: 7256-7265, 2009.

19. Tannock IF, de Wit R, Berry WR, Horti J, Pluzanska A, Chi KN, Oudard S, Théodore C, James ND, Turesson I, et al; TAX 327 Investigators: Docetaxel plus prednisone or mitoxantrone plus prednisone for advanced prostate cancer. N Engl J Med 351: 1502-1512, 2004.

20. Petrylak DP, Tangen CM, Hussain MH, Lara PN Jr, Jones JA, Taplin ME, Burch PA, Berry D, Moinpour C, Kohli M, et al: Docetaxel and estramustine compared with mitoxantrone and prednisone for advanced refractory prostate cancer. N Engl J Med 351: 1513-1520, 2004.

21. Kantoff PW, Higano CS, Shore ND, Berger ER, Small EJ, Penson DF, Redfern CH, Ferrari AC, Dreicer R, Sims RB, et al; IMPACT Study Investigators: Sipuleucel-T immunotherapy for castration-resistant prostate cancer. N Engl J Med 363: 411-422, 2010.

22. Reinis M, Indrová M, Mendoza L, Mikysková R, Bieblová J, Bubeník J and Símová J: HPV16-associated tumours: Therapy of surgical minimal residual disease with dendritic cell-based vaccines. Int J Oncol 25: 1165-1170, 2004.

23. Reinis M, Stepanek I, Simova J, Bieblova J, Pribylova H, Indrova $M$ and Bubenik $J$ : Induction of protective immunity against MHC class I-deficient, HPV16-associated tumours with peptide and dendritic cell-based vaccines. Int J Oncol 36: 545-551, 2010.

24. Indrová M, Reinis M, Bubeník J, Jandlová T, Bieblová J, Vonka V and Velek J: Immunogenicity of dendritic cell-based HPV16 E6/ E7 peptide vaccines: CTL activation and protective effects. Folia Biol (Praha) 50: 184-193, 2004.

25. Lin KY, Guarnieri FG, Staveley-O'Carroll KF, Levitsky HI, August JT, Pardoll DM and Wu TC: Treatment of established tumors with a novel vaccine that enhances major histocompatibility class II presentation of tumor antigen. Cancer Res 56: 21-26, 1996.

26. Foster BA, Gingrich JR, Kwon ED, Madias C and Greenberg NM: Characterization of prostatic epithelial cell lines derived from transgenic adenocarcinoma of the mouse prostate (TRAMP) model. Cancer Res 57: 3325-3330, 1997.

27. Lutz MB, Kukutsch N, Ogilvie AL, Rössner S, Koch F, Romani N and Schuler G: An advanced culture method for generating large quantities of highly pure dendritic cells from mouse bone marrow. J Immunol Methods 223: 77-92, 1999.

28. Stepanek I, Indrova M, Bieblova J, Fucikova J, Spisek R, Bubenik J and Reinis M: Effects of 5-azacytidine and trichostatin A on dendritic cell maturation. J Biol Regul Homeost Agents 25: 517-529, 2011. 
29. Yi AK and Krieg AM: CpG DNA rescue from anti-IgM-induced WEHI-231 B lymphoma apoptosis via modulation of I kappa $\mathrm{B}$ alpha and I kappa B beta and sustained activation of nuclear factor-kappa B/c-Rel. J Immunol 160: 1240-1245, 1998.

30. Reinis M, Símová J, Indrová M, Bieblová J, Pribylová H, Moravcová S, Jandlová T and Bubeník J: Immunization with MHC class I-negative but not -positive HPV16-associated tumour cells inhibits growth of MHC class I-negative tumours. Int J Oncol 30: 1011-1017, 2007.

31. Indrová M, Símová J, Bieblová J, Bubeník J and Reinis M: NK1.1 cells are important for the development of protective immunity against MHC I-deficient, HPV16-associated tumours. Oncol Rep 25: 281-288, 2011

32. Bubenik J, Zeuthen J, Indrova M, Bubenikova D and Simova J: Kinetics and function of peritoneal-exudate cells during local IL-2 gene-therapy of cancer. Int J Oncol 4: 13-16, 1994.

33. Indrová M, Mikysková R, Jandlová T, Vonka V, Bubeník J and Bieblová J: Adjuvant cytokine treatment of minimal residual disease after surgical therapy in mice carrying HPV16-associated tumours: Cytolytic activity of spleen cells from tumour regressors. Folia Biol (Praha) 49: 217-222, 2003.

34. Frey B, Janko C, Ebel N, Meister S, Schlücker E, MeyerPittroff R, Fietkau R, Herrmann M and Gaipl US: Cells under pressure - treatment of eukaryotic cells with high hydrostatic pressure, from physiologic aspects to pressure induced cell death. Curr Med Chem 15: 2329-2336, 2008.
35. Adkins I, Fucikova J, Garg AD, Agostinis P and Špíšek R Physical modalities inducing immunogenic tumor cell death for cancer immunotherapy. Oncoimmunology 3: e968434, 2014.

36. Martini M, Testi MG, Pasetto M, Picchio MC, Innamorati G, Mazzocco M, Ugel S, Cingarlini S, Bronte V, Zanovello P, et al: IFN-gamma-mediated upmodulation of MHC class I expression activates tumor-specific immune response in a mouse model of prostate cancer. Vaccine 28: 3548-3557, 2010.

37. Okamoto $\mathbf{M}$ and Sato $\mathrm{M}$ : Toll-like receptor signaling in anticancer immunity. J Med Invest 50: 9-24, 2003.

38. Reinis M, Símová J, Indrová $\mathbf{M}$, Bieblová $\mathbf{J}$ and Bubeník J: $\mathrm{CpG}$ oligodeoxynucleotides are effective in therapy of minimal residual tumour disease after chemotherapy or surgery in a murine model of MHC class I-deficient, HPV16-associated tumours. Int J Oncol 30: 1247-1251, 2007.

39. Spranger S, Javorovic M, Bürdek M, Wilde S, Mosetter B, Tippmer S, Bigalke I, Geiger C, Schendel DJ and Frankenberger B: Generation of Th1-polarizing dendritic cells using the TLR7/8 agonist CL075. J Immunol 185: 738-747, 2010. 